\title{
Patienten setzten Statine nach Belieben ab
}

\author{
Eine irritierende Patientenentscheidung ist offenbar weit verbreitet: \\ Laut einer Studie unterbricht etwa jeder zweite Patient seine Statin- \\ einnahme für mindestens drei Monate.
}

_Etwa jeder zweite in der Studie betrachtete Patient beendete seine Statineinnahme für mindestens drei Monate. Drei von vier Patienten entschlossen sich danach zu einem Neuanfang.

Ausgewertet wurde ein englisches $\mathrm{Re}$ gister mit Daten von Patienten im Alter von 25-84 Jahren aus 664 Allgemeinarztpraxen. Ihnen wurde zwischen 2002 und 2013 erstmals ein Statin zur Primär $(\mathrm{n}=205.622)$ oder Sekundärprävention $(\mathrm{n}=139.314)$ verordnet. Die mittlere Beobachtungsdauer betrug drei Jahre. Ein Abbruch der Behandlung wurde angenommen, wenn innerhalb von 90 Tagen nach dem errechneten Tablettenverbrauch keine neue Statinabgabe erfolgte. Dies war bei $47 \%$ der Patienten in der Primärprävention der Fall. Nach dieser Unterbrechung nahmen innerhalb der Studiendauer 72\% der Patienten das Statin wieder ein. Die Zahlen bei Sekundärprävention lagen mit $41 \%$ bzw. $75 \%$ in der gleichen Größenordnung.

Interessant ist der Blick auf einzelne Gruppen im Vergleich zum Gesamtkollektiv. Am günstigsten schnitten Hypertoniker und Typ-2-Diabetiker ab: Sie tendierten seltener zum Abbruch, die Abbrecher unter ihnen vermehrt zum Neustart. Am ungünstigsten verhielten sich Patienten unter 50 bzw. über 75 Jahren, untergewichtige und leberkranke Patienten sowie solche, die viele Medikamente einnahmen. In diesen Gruppen gab es mehr Abbrüche und weniger Neustarts. Andererseits galt für Raucher und Typ-1-Diabetiker: mehr Abbrüche, aber häufiger ein Neubeginn.

- Vinogradova Y et al. Discontinuation and restarting in patients on statin treatment: prospective open cohort study using a primary care database. BMJ. 2016;353:i3305

\section{KOMMENTAR}

In dieser Studie geht es nicht um gelegentliche mangelhafte Therapietreue infolge von Nachlässigkeit und Vergesslichkeit, sondern um das bewusste, eigenmächtige Absetzen ärztlich verordneter Medikamente über mindestens drei Monate oder länger. Fast jeder zweite Patient trifft diese Entscheidung im Hinblick auf Statine innerhalb von drei Jahren nach Therapiebeginn. Auch wenn etwa drei von vier dieser Patienten die Therapie wieder aufnehmen, bleiben 10-12\% langfristig ohne diese Therapie.

Man gewinnt den Eindruck, dass Therapieverweigerer teils nachvollziehbare

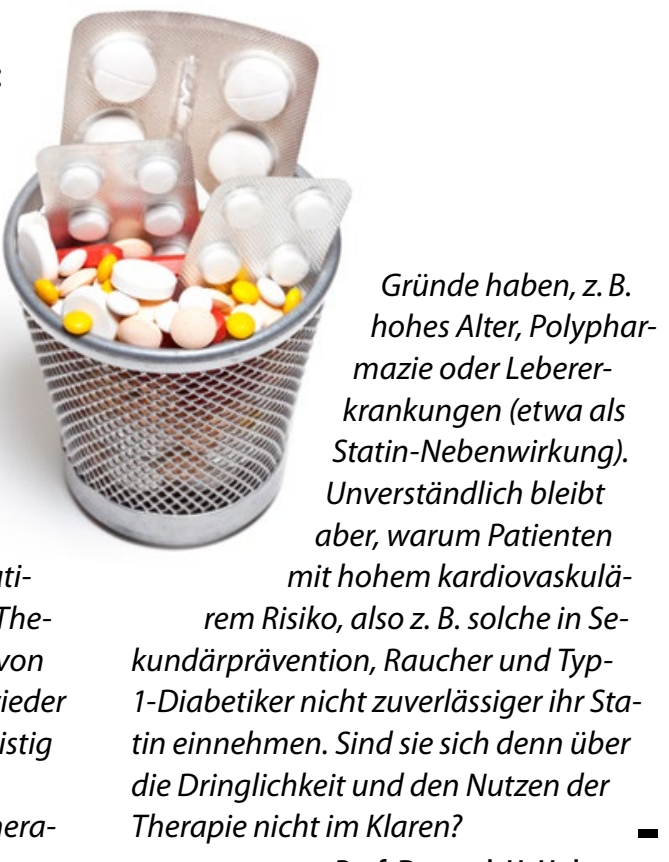

Prof. Dr. med. H. Holzgreve

ANZEIGE

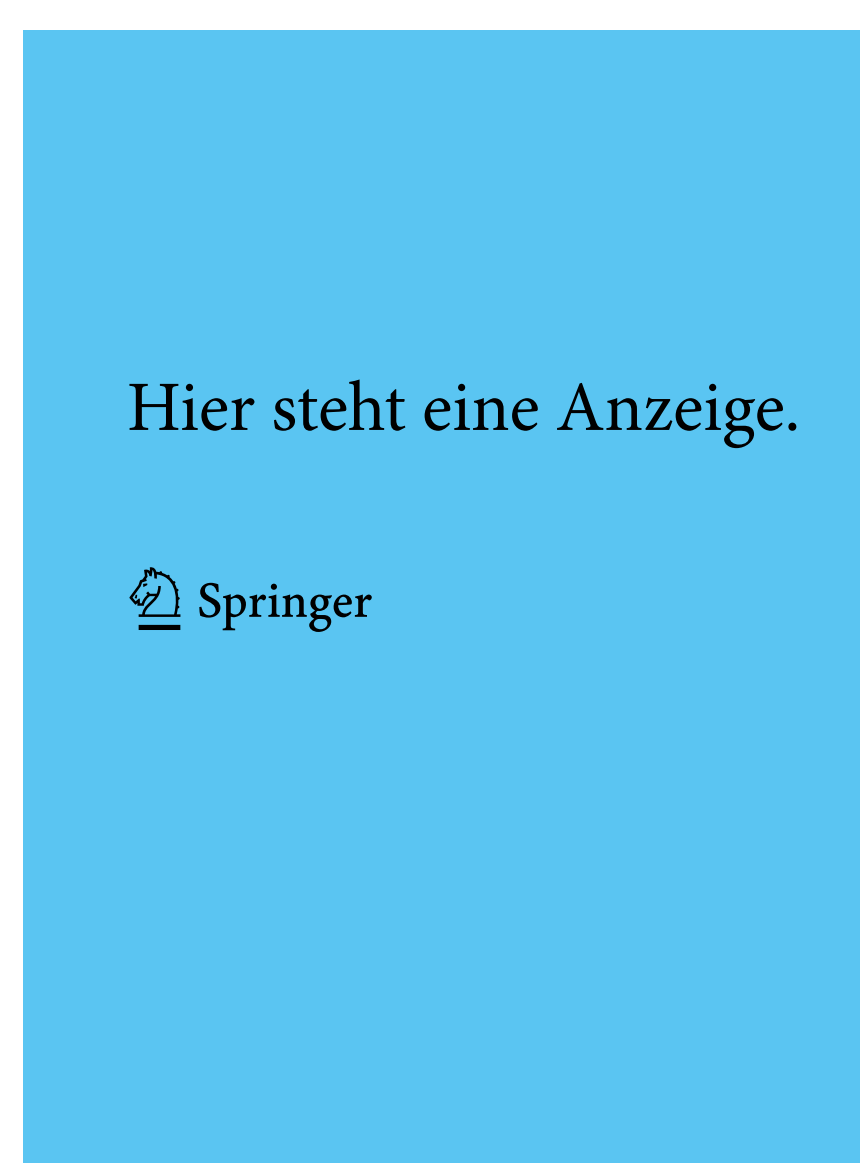

